\title{
UNIVERSOS FUNCIONAM COMO GRANDE CÉREBRO?
}

Arnaldo Pinto Guedes de Paiva Neto

\begin{abstract}
Graduado em Medicina pela Universidade Federal de Alagoas (UFAL) Instituição: Faculdade de Medicina (FAMED) / Hospital Universitário Prof. Alberto Antunes (HUPAA). E-mail: arnaldopneto93@gmail.com
\end{abstract}

\section{RESUMO}

$\mathrm{O}$ artigo põe em debate se haveria uma forma científica de explicar a existência de Deus ou deuses. O objetivo do trabalho é responder se diferentes religiões e crenças poderiam se aliar de forma pacífica com o cientificismo. Há uma necessidade constante de diplomacia para que sobrevivamos aos sentimentos impostos pela convivência em sociedade. A nossa proposta é de sermos um movimento intelectual, bioético e científico que tente encontrar um "denominador comum" para as diferentes formas de interpretar a existência e amparar a solidão que sentimos, visto que o Universo também tem sentimentos. A visão científica deste trabalho é em defesa da existência de diversas formas de interpretar os fatos científicos e religiosos. $\mathrm{O}$ estudo se baseia nos princípios de liberdade religiosa e dignidade humana. A evolução da humanidade caminha lado a lado com a conciliação entre os povos e enaltecimento dos direitos humanos.

PALAVRAS-CHAVE: Filosofia. Filosofia da Mente. Complexidade.

\section{UNIVERSES WORKS LIKE A BIG BRAIN?}

\begin{abstract}
The article questions whether there is a scientific way of explaining the existence of God or gods. The aim of the work is to answer whether different religions and beliefs could peacefully ally with scientism. There is a constant need for diplomacy so that we can survive the feelings imposed by living in society. Our proposal is to be an intellectual, bioethical and scientific movement that tries to find a "common denominator" for the different ways of interpreting existence and supporting the loneliness that we feel, since the Universe also has feelings. The scientific view of this work is in defense of the existence of different ways of interpreting scientific and religious facts. The study is based on
\end{abstract}


the principles of religious freedom and human dignity. The evolution of humanity goes hand in hand with reconciliation between peoples and the enhancement of human rights.

KEYWORDS: Philosophy. Philosophy of Mind. Complexity.

\section{INTRODUÇÃO}

“A crença na existência em Deus, ou deuses, está presente em todas as civilizações humanas. Então, é evidente: o homem e a mulher são animais espirituais" (MARQUES, 2016, p. 46). As formas de religiosidade são diversas entre si, embora haja semelhanças entre muitas delas (MACHADO, 1996, p. 2). Para defendermos a paz entre diferentes crenças, precisamos ressaltar também o que elas têm em comum: a capacidade de acreditar na origem divina ou mística. Considerando essa veracidade como coletiva, podemos admitir que cada doutrina religiosa possua a sua autenticidade. Podemos viver em um mundo que apresenta mais de uma verdade e que necessariamente não torne a outra interpretação mentira. Porque ideias distintas não precisam se anular. Voltemo-nos novamente para o pensamento comum: se o Universo funcionasse como Grande Cérebro, cada pessoa poderia chamar o Universo de Deus ou deuses e não estariam erradas, seriam formas dissemelhantes de traduzir o mesmo Universo.

O universo é "autoconsciente" e é a própria consciência que cria o mundo físico (GOSWAMI, 2015, p. 13). Com o início da compreensão de que o Universo poderia pensar, ao contrário da perspectiva de que o Universo não faria sentido, nos aproximamos da ideia de religião cósmica de Albert Einstein. Precisa-se de um paradigma que sustente a relação entre a metafísica espiritual e a ciência do mundo material (MARQUES, 2016, p. 47). "A religião cósmica é o móvel mais poderoso e mais generoso da pesquisa científica" (EINSTEIN, 1953, p. 13). O artigo defende o pressuposto de que existe a Mente Universal análoga ao cérebro humano, a qual se encarregaria de manter a sincronia cronológica (no ponto de vista da Teoria da Relatividade Geral) e possibilitar que a dimensão do tempo se mantenha em ordem. É confrontada também neste trabalho a visão ateísta de que a ideia da crença em Deus ou deuses poderia ser fruto da ilusão humana.

\section{METODOLOGIA}

O trabalho desenvolvido trata-se de uma revisão bibliográfica, por meio de livros e artigos de periódicos na área. Textos que estão disponíveis em meios digitais. Os principais 
teóricos escolhidos foram: Albert Einstein (1953), através da sua perspectiva de ver o mundo. Arnaldo Paiva Neto (2017), que nos traz a explicação de como o Universo poderia funcionar como Grande Cérebro. Juracy Marques (2016), por saber lidar com as diferenças culturais e religiosas de forma pacífica. Amit Goswami (2015), que tem conseguido conciliar conceitos físicos com metafísicos, unindo a espiritualidade com o cientificismo.

\section{O MODELO FÍSICO, AS PARTÍCULAS ELEMENTARES E A RELATIVIDADE}

No modelo padrão físico de partículas, baseado em pressupostos básicos, foi indicado que há uma simetria importante em comparações precisas das propriedades fundamentais do conjugado matéria com antimatéria (SMORRA, 2016, p. 371). Por essa razão, os cientistas concluíram que o Universo não deveria existir. Alguns estudiosos supõem que há alguma assimetria. Mesmo com a tendência não existencial do Cosmos, sabemos da sua realidade assim como "pensamos, logo existimos".

O espectro sem escala de perturbações de densidade que poderia explicar a origem das galáxias e todas as outras estruturas no Universo, baseados nos estudos de Halliwell e Hawking (1985), apresenta-se em uma beleza maior quando admitimos que há um padrão existencial que superou as forças contrárias à matéria. $\mathrm{O}$ vácuo, visto como aniquilação que ocorre na união da matéria com sua antimatéria, pode gerar partículas elementares. Tryon (1973) apresenta um trabalho sobre essa indagação "se o Universo é uma flutuação do vácuo". Nesse contexto, o Cosmos assume atributo de originar-se através da unificação das teorias da física. Originar-se é uma característica divina.

Comparar o Universo com Grande Cérebro é relacionar os princípios da Teoria da Relatividade que existem na mente humana e no Universo. O tempo sempre foi um tema que possibilita o despertar da criatividade em textos e trabalhos. Dahmen (2006) cita Hawkings (1992) de uma forma bem-humorada se referindo ao fato de que 'não fomos invadidos por uma horda de turistas do futuro' e que isso nos mostra que o tempo se mantém em ordem ou que há uma conjectura [de proteção cronológica], embora o tempo passe de maneira desigual. O tempo passa sutilmente mais devagar no solo do que na atmosfera, porque a curvatura da malha flexível do espaço-tempo gerada pela gravidade é sutilmente maior no solo do que na atmosfera.

Pesquisadores conseguiram mostrar que as estrelas se comportavam como propõe a relatividade geral, confirmando a curvatura do espaço-tempo gerada pela presença de matéria 
(ANTONIADIS, 2013). Foi comprovado cientificamente, através da comparação de dois relógios atômicos: um no solo em repouso e outro na atmosfera que o tempo passa mais devagar no solo em relação à atmosfera (CATTANI, 2010).

\section{O SISTEMA UNIVERSAL DE MEMÓRIA}

Imaginemos que dois indivíduos, um no solo e outro na atmosfera, tentam se comunicar por celular. Se houvesse o grande acúmulo das diferenças do tempo que se passa na superfície em relação ao tempo que se passa nas alturas, o solo estaria mais atrasado em relação à atmosfera. Essas diferenças que existem no tempo não se (super) acumulam o suficiente para evitar a comunicação ou sincronia entre os dois indivíduos em questão. Podemos imaginar uma ficção científica, caso o tempo que se passa na superfície se diferenciasse demais em relação ao tempo que se passa nas maiores altitudes.

Isto é, se o solo se atrasasse demais em relação à atmosfera, quando o jovem que estivesse no chão ligasse para o idoso que estivesse nas alturas para dizer "bom dia", estaria de noite na atmosfera. O idoso responderia "boa noite". Arnaldo Paiva Neto (2017) defendeu que existe um "princípio de sincronia" que explica porque o tempo que se passa no solo do planeta Terra não super acumula pequenas diferenças de atraso o suficiente para tornar-se muito atrasado (cerca de uma hora, por exemplo) em relação ao tempo que se passa na atmosfera.

Se a fluidez do tempo for comparada com carros indo de um ponto da estrada a outro lugar, o trânsito ocorre de forma tão magnífica que não há engarrafamento entre os carros. Entre o céu e a terra existe uma sincronia no que diz respeito às alterações do tempo, tal fenômeno é claramente observado através da simultaneidade que ambos respondem ao pôr do sol, por exemplo. Existe também um princípio de sincronia que ocorre em nossos cérebros. Há curto período do tempo (na fração do segundo) em que nossos nervos enviam o impulso ao cérebro. Imagina um trânsito de carros.

Cada carro representa o impulso nervoso até chegar ao cérebro. Leva um tempo na fração do segundo para o impulso chegar ao cérebro. É um trânsito que não fica "engarrafado". Não ocorre o "super" acúmulo dos ínfimos atrasos dos impulsos nervosos até o cérebro. É como se os carros trafegassem com o sinal "verde". A memória impede que se acumule esse atraso, os restos atrasados são transformados em memória e há sincronia entre nós e as novas ocorrências no ambiente externo.

Os impulsos nervosos não engarrafam como carros parados no sinal vermelho. É como 
se a memória fosse um botão que mantém o sinal verde. Nós não nos perdemos no tempo, porque memorizamos o que ocorre nele e nos sincronizamos com as novas ocorrências no próprio tempo. Então, a memória funciona como uma grandeza de proteção cronológica. $\mathrm{O}$ mecanismo da memória nos nossos cérebros funciona da mesma maneira que o mecanismo de sincronia do tempo.

Descobrir um mecanismo que exista no cérebro e que também exista no Cosmos é o primeiro passo para uma nova forma de interpretar os fatos. Não há outro modo de constatar objetivamente que tudo, inclusive a mente e a consciência, surge da matéria (GOSWAMI, 2015, p. 18). "O que sincroniza duas percepções do tempo de indivíduos em alturas que sofrem diferentes influências da gravidade é a constante de memória do meio externo" (DE PAIVA NETO, 2017). Por essa razão, foi suposta a existência de um Sistema Universal de Memória.

\section{DENOMINADOR COMUM ENTRE AS RELIGIÕES E A CIÊNCIA}

Nesse contexto, podemos compreender o que é sintetizado por Albert Einstein (1953), quando ele adota o termo religiosidade cósmica. A ciência moderna está se aventurando por reinos que durante mais de quatro milênios foram os feudos da religião e da filosofia. Será o universo apenas uma série de fenômenos objetivamente previsíveis, que a humanidade observa e controla, ou será muito mais esquivo e até mais maravilhoso? (GOSWAMI, 2015, p. 85).

Ou será que Deus foi uma palavra que, como todas as outras palavras, se originou a partir do funcionamento do cérebro humano? Antes dos seres humanos existirem, não existiam tais vocábulos. As definições se originaram, assim como o conceito de Deus, com a nossa espécie (ALPER, 2008, p. 60). Nos levando a questionar se seriam as divindades criadas pela nossa mente, assim como os conceitos da linguagem e escrita foram elaborados por nós.

As necessidades religiosas e a ânsia pelo pai derivam do desamparo da criança. Esse sentimento é sustentado de modo permanente pelo medo do poder superior do destino (FREUD, 1974). O fato de que precisamos emocionalmente da religião não significa que ela seja ilusão. Muitas das fantasias e carências que temos são formas pessoais de interpretarmos objetos reais e nem por isso, esses objetos são fictícios. Existem diferentes maneiras aceitas de descrever um mesmo objeto. Algumas perspectivas ateístas defendem que as religiões são criações mentais e seus conteúdos seriam ilusão, baseadas no fato de que temos necessidades emocionais de fantasiar.

No momento em que estamos dispostos a tratar o termo "sentimento religioso" como 
um nome coletivo para os muitos sentimentos que os objetos religiosos podem despertar em alternância, vemos que provavelmente não contém nada de natureza psicologicamente específica (JAMES, 1985, p. 31). Nós inferimos que a percepção religiosa é relativa para cada indivíduo. Ressaltamos a questão de que a tolerância entre diversas doutrinas deve levar em consideração o significado individual e vivenciado da prática entre as discordantes culturas.

Matthew Alper (2008) escreveu seu livro intitulado The "God" Part of the Brain: A Scientific Interpretation of Human Spirituality and God, em que explica que os seres humanos são geneticamente predispostos a acreditar nos conceitos religiosos como resultado de uma adaptação evolutiva para sobrevivência. Juracy Marques (2016, p. 22) ao citar Alper, destaca: 'mas a natureza programaria uma espécie, embutindo nela uma mentira?' Se a capacidade intuitiva de crer da humanidade fosse mentira, não haveria como a raça humana ter alcançado tantos progressos, através de riscos que os pensadores correram por acreditarem naquilo que não poderiam ter certeza que daria certo.

A religiosidade do sábio consiste em espantar-se, em extasiar-se diante da harmonia das leis da natureza, revelando uma inteligência tão superior que todos os pensamentos humanos e todo seu engenho não podem desvendar, diante dela, a não ser seu nada irrisório (EINSTEIN, 1953, p. 13). Infunde-se em nós uma nova visão do mundo, em que recorremos à ciência e à religião e pedimos aos praticantes de ambas que se reúnam a nós como co-investigadores e copromotores de uma nova ordem (GOSWAMI, 2015, p. 262).

Arnaldo Paiva Neto (2017) defende que o equilíbrio temporal ou sincronia, propriedade da mente, pode ocorrer no Universo. Os ambientes externos de um mesmo corpo celeste são "sincronizados" na unidade internacional do segundo (para o planeta Terra) ou outras unidades considerando astros de gravidades extremas, da mesma forma que a percepção do tempo de um indivíduo com as ocorrências no ambiente externo é sincronizada pela grandeza mental de memória (DE PAIVA NETO, 2017). O mesmo princípio de sincronia que se aplica para o Universo (baseado na Teoria da Relatividade) também ocorre no Cérebro humano.

Para construção da tese de que o Universo funciona como Grande Cérebro (Deus ou deuses) é fundamental a defesa da liberdade religiosa, direitos humanos, amor e respeito entre crenças. Talvez as crenças possam ser causalmente eficazes, e seu conteúdo é relevante para o comportamento que elas geram, enquanto o comportamento assim gerado é inadaptado (PEIRCE, 1877, p. 312).

As doutrinas influenciam nas atitudes das pessoas. Quando defendemos uma ideia em 
comum às religiões, buscamos sugestionar a dinâmica das experiências interpessoais. $\mathrm{O}$ conceito de poder o Universo funcionar como Mente tem experimentalmente a capacidade de modificar a forma como as pessoas encaram as disparidades em um mundo cada vez mais globalizado. Há uma necessidade constante de diplomacia para que sobrevivamos aos sentimentos impostos pela convivência em sociedade. A temática religiosa saudável busca estabelecer uma forma harmoniosa de convívio social, desenvolvimento da civilização e relação com o meio ambiente equilibrada. Na prática, toda crença que possibilita que as pessoas vivam em paz é válida. Está escrito em COMPARATO (2001):

O que se conta, nestas páginas, é a parte mais bela e importante de toda a História: a revelação de que todos os seres humanos, apesar das inúmeras diferenças biológicas e culturais que os distinguem entre si, merecem igual respeito. Como únicos entes no mundo capazes de amar, descobrir a verdade e criar a beleza. E o reconhecimento universal de que, em razão dessa radical igualdade, ninguém - nenhum indivíduo, gênero, etnia, classe social, grupo religioso ou nação - pode afirmar-se superior aos demais.

Existe uma natureza humana universal que pode ser reconhecida racionalmente (SANTOS, 1997). Defendemos um caráter suficientemente protetor para preservar a vida e a existência material ou relutante ao fim destas. O que é, em essência, a mais sublime e eterna forma de lembrança do Universo: toda existência é sempre útil, a vida sempre vale a pena (DE PAIVA NETO, 2017). Nós somos consciência. Todo o mundo da experiência, inclusive a matéria, é a manifestação material de formas transcendentais de consciência (GOSWAMI, 2015). Deus é, mora na Natureza, com a qual se têm contato, interconectam-se (MARQUES, 2016, p. 87). A nossa proposta é de sermos um movimento intelectual, bioético e científico que tente encontrar um "denominador comum" para as diferentes formas de interpretar a existência, aliado a busca incessante pela paz. Visto que somos daqueles que acreditam que o mundo em que vivemos pode ser melhor. A humanidade pode conviver nos princípios pacifistas.

\section{CONSIDERAÇÕES FINAIS}

A ideia proposta nesse trabalho reafirma o conceito de unicidade: somos componentes da mesma Humanidade; religiões e ciências podem ser guiadas pelo ponto de vista racional; é possível a coexistência de diferentes verdades, sem que uma interpretação religiosa desvalide a outra e; podemos alcançar um senso comum que vise estabelecer relações pacíficas e sociais. 
Concluímos que o Universo pode funcionar como Grande Cérebro e que cada indivíduo tem o direito de atribuir qual nome desejar a esse Deus ou deuses.

De forma prática, as crenças influenciam nos comportamentos das pessoas. $\mathrm{O}$ aprofundamento teórico mostrado anteriormente é fundamentado na possibilidade de considerar que cada doutrina religiosa possua a sua autenticidade e que possam compartilhar em comum a noção de Universo com caráter divino. O sentimento religioso é relativo e pessoal. Devemos considerar a convivência, tolerância e liberdade religiosa como meta a ser alcançada no mundo atual. Através da leitura dos artigos e livros, podemos compreender que está havendo um processo de mudança nos conceitos relacionados ao tema das ciências e religiões. Cada vez mais, o mundo caminha em uma direção com a conciliação entre os povos e enaltecimento dos direitos humanos.

\section{REFERÊNCIAS BIBLIOGRÁFICAS}

ALPER, Matthew. The" God" Part of The Brain: A Scientific Interpretation of Human Spirituality and God. Sourcebooks, Inc., 2008.

ANTONIADIS, John et al. A Massive Pulsar in a Compact Relativistic Binary. Science, v. 340, n. 6131, p. 1233232, 2013.

CATTANI, M. Einstein Gravitation Theory: Experimental Tests I. arXiv preprint arXiv:1005.4314, 2010.

COMPARATO, Fábio Konder. A Afirmação Histórica dos Direitos Humanos. Saraiva, 2001.

DE PAIVA NETO, Arnaldo Pinto Guedes. A Gênese Biofísica da Memória. Revista Ouricuri, v. 6, n. 2, p. 042-054, 2017.

EINSTEIN, Albert. Como Vejo o Mundo. Ed. Nova Fronteira, São Paulo/SP, 1953.

FREUD, Sigmund. O Futuro de uma Ilusão (1927). Rio de Janeiro: Imago, 1974.
GOSWAMI, Amit. $O$ Universo Autoconsciente: Como a Consciência Cria o Mundo Material. Aleph, 2015.

GOSWAMI, Amit. A Física da Alma: A Explicação Científica Para a Reencarnação, a Imortalidade $e$ as Experiências de Quase Morte. Aleph, 2015.

HALLIWELL, Jonathan J.; HAWKING, Stephen William. Origin of Structure in the Universe. Physical Review D, v. 31, n. 8, p. 1777, 1985.

HAWKING, Stephen W. Chronology Protection Conjecture. Physical Review D., v. 46, n. 2, p. 603, 1992.

JAMES, William. The Varieties of Religious Experience. Harvard University Press, 1985.

MACHADO, Jónatas Eduardo Mendes. Liberdade Religiosa Numa Comunidade Constitucional Inclusiva: dos Direitos. 1996.

MARQUES, Juracy. Ecologia do Espírito. Petrolina: Gráfica Franciscana, 2016. 
PEIRCE, Charles Sanders. The Fixation of Belief, 1877.

SANTOS, Boaventura de Souza. Uma Concepção Multicultural de Direitos Humanos. Lua nova, v. 39, p. 105-124, 1997.
SMORRA, C. et al. A Parts-per-Billion Measurement of the Antiproton Magnetic Moment. Nature, v. 550, p. 371-374, 2016.

TRYON, Edward P. Is The Universe a Vacuum Fluctuation? Nature, v. 246, n. 5433, p. 396-397, 1973.

NETO, A. P. G. P. Universos Funcionam Como Grande Cérebro? Complexitas - Rev. Fil.

Tem. Belém, v. 5, n. 1, p. 96-104, jan./dec. 2020. Disponível em: http://www.periodicos.ufpa.br/index.php/complexitas/article/view/6956>. Acesso em: $01 \mathrm{de}$ novembro de 2020. 